\title{
The effects of $\mathrm{Ba}^{2+}$ content on depolarization temperature and pyroelectric properties of lead-free $0.94 \mathrm{Na}_{0.5} \mathrm{Bi}_{0.5} \mathrm{TiO}_{3}-$ $\mathrm{O.06Ba}_{1+\mathrm{x}} \mathrm{TiO}_{3}$ ceramics
}

\author{
A. M. Balakt ${ }^{1} \cdot$ C. P. Shaw ${ }^{1} \cdot$ Q. Zhang ${ }^{1}$
}

Received: 4 May 2016/ Accepted: 25 July 2016/Published online: 11 August 2016

(c) The Author(s) 2016. This article is published with open access at Springerlink.com

\begin{abstract}
Lead-free $\quad 0.94 \mathrm{Na}_{0.5} \mathrm{Bi}_{0.5} \mathrm{TiO}_{3}-0.06 \mathrm{Ba}_{1+\mathrm{x}} \mathrm{TiO}_{3}$ $\left(\mathrm{NBT}-0.06 \mathrm{~B}_{1+\mathrm{x}} \mathrm{T}\right)$ ceramics $(0.0 \leq \mathrm{x} \leq 0.03)$ were synthesized by a conventional solid-state reaction process. X-ray diffraction shows that the compositions are at the morphotropic phase boundary where rhombohedral and tetragonal phase coexist. Grain size slightly changes with the increase of $\mathrm{Ba}^{2+}$ content and reaches the minimum at $\mathrm{x}=0.02$. The depolarization temperature $\left(T_{d}\right)$ decreases with the extra $\mathrm{Ba}^{2+}$ content but the lowest $T_{d}$ was obtained at $\mathrm{x}=0.01-0.02$. The pyroelectric coefficient $(p)$ was measured as a function of $\mathrm{Ba}^{2+}$ content, and increased from $2.90 \times 10^{-4}$ to $3.54 \times 10^{-4} \mathrm{C} \mathrm{m}^{-2}{ }^{\circ} \mathrm{C}^{-1}$, and from $55.3 \times 10^{-4}$ to $740.7 \times 10^{-4} \mathrm{C} \mathrm{m}^{-2}{ }^{\circ} \mathrm{C}^{-1}$ for $\mathrm{x}=0.00$ and 0.02 at RT, and depolarization temperature $\left(T_{d}\right)$ respectively. The pyroelectric coefficient $(p)$ shows a large increase with rising the temperature and reaches the maximum value at the depolarization temperature $\left(T_{d}\right)$. The figures of merits of $\boldsymbol{F}_{\boldsymbol{i}}, \boldsymbol{F}_{\boldsymbol{v}}$ and $\boldsymbol{F}_{\boldsymbol{D}}$ have all been improved with the addition of extra barium. These improved pyroelectric properties indicate that NBT$0.06 \mathrm{~B}_{1+\mathrm{x}} \mathrm{T}$ is a promising material for pyroelectric applications or a wide range of temperature.
\end{abstract}

\section{Introduction}

At present the most widely used ferroelectric materials are lead-based ceramics such as PZT and PZT-based multicomponent ceramics due to their superior piezoelectric and electrical properties, but there are two serious

Q. Zhang

q.zhang@ cranfield.ac.uk

1 School of Aerospace, Transport and Manufacturing, Cranfield University, Cranfield, Bedfordshire MK43 0AL, UK environmental problems arising from the fabrication of lead-containing materials: atmospheric pollution caused by $\mathrm{PbO}$ vapour during ceramic fabrication, and the difficulty in removing lead during component recycling. Lead-containing electronic products have been banned in WEEE (waste electrical and electronic equipment) and ROHS (restriction of use of certain hazardous substances) legislation [1]. Therefore there is a need to develop lead-free materials with properties comparable to lead-based ceramics. Among the lead-free materials, sodium bismuth titanate $\left(\mathrm{Na}_{0.5} \mathrm{Bi}_{0.5} \mathrm{TiO}_{3}\right.$, (NBT)) and NBT-based materials are considered to be an important material for the fabrication of lead-free material [2-5] due to their excellent ferroelectric and dielectric properties [5]. Large efforts of investigation on NBT-based materials for their piezoelectric applications have been made while there have been limited reports on their pyroelectric properties.

Pyroelectric ceramic materials are becoming increasingly on high demand in variety of industrial applications such as sensors, infrared detectors, thermal cameras, gas detectors, microelectronic devices, as well as actuators, transducers, medical devices, airplanes and spacecraft [6]. These materials could have a large pyroelectric coefficient (polarization change vs temperature change) at a phase transition temperature. NBT exhibits two structural phase transitions: the first one $\left(T_{d}\right)$ from a ferroelectric rhombohedral to a tetragonal phase $\left(\sim 260-350{ }^{\circ} \mathrm{C}\right)$ and the second one $\left(T_{c}\right)$ from a tetragonal phase to a paraelectric cubic phase $\left(520-540{ }^{\circ} \mathrm{C}\right)$. These phase transition temperatures are well above room temperature. Hence it is necessary to bring the phase transition temperature down to near room temperature $(R T)$ for many applications, and that can be achieved by using various dopants [7]. In NBT-based systems, there is a weakly polar intermediate phase [8], 
which occurs between the depolarization temperature $T_{d}$ and the temperature of maximum permittivity $\left(T_{m}\right)$ [9-12].

$(1-\mathrm{x})\left(\mathrm{Na}_{0.5} \mathrm{Bi}_{0.5}\right) \mathrm{TiO}_{3}-\mathrm{xBaTiO}_{3}$ has a morphotropic phase boundary at $\mathrm{x}=0.06-0.07$ [13] and its depolarization temperature $\left(T_{d}\right)$ is $\sim 123{ }^{\circ} \mathrm{C}$ and well below its phase transition temperature $\left(T_{m}\right)$ which is around $300{ }^{\circ} \mathrm{C}$. Jo et al. [14] reported that $T_{d}$ could be the phase transition temperature from ferroelectric to relaxor or from rhombohedral ferroelectric to tetragonal ferroelectric [12]. This phase transition at $T_{d}$ may induce a large pyroelectric effect. Guo et al. [15] studied the pyroelectric properties of $(1-\mathrm{x}) \mathrm{NBT}-\mathrm{xBa}(\mathrm{ZrTi}) \mathrm{O}_{3}(0 \leq \mathrm{x} \leq 0.12)$ ceramics and found that the pyroelectric coefficient was enhanced from $0.057 \mu \mathrm{C} \mathrm{cm}^{-2}{ }^{\circ} \mathrm{C}^{-1}$ at $R T$ to $2.21 \mu \mathrm{C} \mathrm{cm}^{-2}{ }^{\circ} \mathrm{C}^{-1}$ at $T_{d}$ $\left(87^{\circ} \mathrm{C}\right)$. In this work, we aim to bring down the $T_{d}$ by varying the $\mathrm{Ba}^{2+}$ content in $0.94\left(\mathrm{Na}_{0.5} \mathrm{Bi}_{0.5}\right) \mathrm{TiO}_{3}-$ $0.06 \mathrm{Ba}_{1+\mathrm{x}} \mathrm{TiO}_{3}\left(\mathrm{NBT}-0.06 \mathrm{~B}_{1+\mathrm{x}} \mathrm{T}\right)$ ceramics and to investigate the effect of $\mathrm{Ba}^{2+}$ content on the depolarization temperature, and the subsequent dielectric and pyroelectric properties at $T_{d}$.

\subsection{Experimental}

A solid state synthesis route was used to prepare NBT$0.06 \mathrm{~B}_{1+\mathrm{x}} \mathrm{T}$ composition. The raw materials used in this project were powders, bismuth oxide $\left(\mathrm{Bi}_{2} \mathrm{O}_{3}, 99.999 \%\right)$, sodium carbonate $\left(\mathrm{Na}_{2} \mathrm{CO}_{3}, 99.5 \%\right)$, barium carbonate $\left(\mathrm{BaCO}_{3}, 99.98 \%\right)$, and Titanium dioxide $\left(\mathrm{TiO}_{2},>99.8 \%\right)$. All chemicals were purchased from Sigma-Aldrich, UK.

The amounts of powders were calculated according to the chemical formula of $0.94 \mathrm{Na}_{0.5} \mathrm{Bi}_{0.5} \mathrm{TiO}_{3}-0.06 \mathrm{Ba}_{1+-}$ ${ }_{x} \mathrm{TiO}_{3}$ with $\mathrm{x}=0.00,0.01,0.02$, and 0.03. The raw materials were ball-milled in acetone for $24 \mathrm{~h}$. in order to mix and mill the powders. The resultant slurries were dried at $50{ }^{\circ} \mathrm{C}$ for $8 \mathrm{~h}$. The dried powder cakes were ground in a mortar for $10 \mathrm{~min}$. and sieved through a $250 \mu \mathrm{m}$ mesh in order to aid the calcination. The powders were calcined at $850{ }^{\circ} \mathrm{C}$ for $180 \mathrm{~min}$ at a heating ramp rate of $1{ }^{\circ} \mathrm{C}$ per min and cooling rate $5{ }^{\circ} \mathrm{C}$ per min in a furnace. After calcination, powders were re-milled for $24 \mathrm{~h}$. in acetone, and $2 \%$ of poly vinyl alcohol (PVA) was added as an organic binder to the dried powders to enhance the mechanical strength of the particles. After that the powders were dried in oven at $80{ }^{\circ} \mathrm{C}$ until fully dried. The dried powders were ground and sieved and subsequently pressed into green pellets with a diameter of $10 \mathrm{~mm}$ under an uniaxial compaction with load $\sim 78 \mathrm{MPs}$ for $5 \mathrm{~min}$ at RT. The pellets were sintered at temperatures up to $1150{ }^{\circ} \mathrm{C}$ in closed crucibles in order to minimize the loss of volatile $\mathrm{Na}^{+}$and $\mathrm{Bi}^{3+}$. The pellets were manually wet polished on both sides using silicon carbide paper to improve uniformity and dried at $100{ }^{\circ} \mathrm{C}$ overnight to remove the moisture. Silver conductive paint (RS limited) was used to electrode the pellets, and electrical poling at $5.5-6 \mathrm{kV} / \mathrm{mm}$ for $10 \mathrm{~min}$ at RT in silicone oil was carried out using a Keithley (6517 Electrometer/high resistance) dc power supply.

SEM (FEI XL30 SFEG) was used to look at the surface morphology of the sintered samples and X-Ray Diffraction (XRD) (Siemens Ltd Model: D500) was used to investigate microstructure. As part of the electrical characterisation of the materials, dielectric measurements were made using an impedance analyser (Wayne kerr Electronics Ltd. Model 3245 and Hewlett Packard HP4092A). Dielectric data was collected over a temperature range from $\mathrm{RT}$ to $150{ }^{\circ} \mathrm{C}$ using a temperature controlled hotplate in the frequency range of $0.1-10 \mathrm{kHz}$. Pyroelectric measurements were made using the ByerRoundy [16] method at the temperature between 20 and $90{ }^{\circ} \mathrm{C}$ (equipment up limitation) under vacuum and the pyroelectric current was collected by a Kiethley electrometer (Model 6217). Dielectric and pyroelectric data was then used to study the phase changes such as depolarization temperatures $\left(T_{d}\right)$, and to determine figure of merit values $F_{i}, F_{v}$ and $F_{D}$.

Sample compositions are listed in Table 1.

\section{Results and discussion}

\subsection{Effects of extra barium on microstructure}

Figure 1 shows the XRD patterns of $0.94 \mathrm{NBT}-0.06 \mathrm{~B}_{1+\mathrm{x}} \mathrm{T}$ $\left(\mathrm{NBT}-0.06 \mathrm{~B}_{1+\mathrm{x}} \mathrm{T}\right)$ ceramic powders calcined at $850{ }^{\circ} \mathrm{C}$ for $3 \mathrm{~h}$. Figure 1a showed that all ceramic samples have a pure perovskite structure $\left(\mathrm{ABO}_{3}\right)$ and no second phase was observed. The absence of other phase indicates that NBT$0.06 \mathrm{~B}_{1+\mathrm{x}} \mathrm{T}$ lattices have either absorbed the extra amount of Barium $\left(\mathrm{Ba}^{2+}\right)$, and formed the $\mathrm{NBT}-0.06 \mathrm{~B}_{1+\mathrm{x}} \mathrm{T}$ ceramic solid solutions $[17,18]$ or the amount of the second phase is too small to be tested by XRD. Figure 1 shows, in all the samples, a splitting in the peak [111] into [003] and [021] at $39.0^{\circ}-41.0^{\circ}$, indicating the existence of rhombohedral phase (Fig. 1b) and a splitting in the peak [200] into [200] and [002] at $45.0^{\circ}-48.0^{\circ}$, indicating the existence of tetragonal phase (Fig. 1c). The coexistence of both rhombohedral and tetragonal phases in $\mathrm{NBT}-0.06 \mathrm{~B}_{1+\mathrm{x}} \mathrm{T}$ ceramics proves that the sample structures are at morphotropic phase boundary $(M P B)$, which was consistent with what was reported in literature [12, 14, 19]. Figure 1c shows that the splitting in peak [200] became quite pronounced for the sample at $x=0.02$ as shown in Fig. 1b. It seems that the composition of $\mathrm{NBT}-0.06 \mathrm{~B}_{1+\mathrm{x}} \mathrm{Ti}$ with $\mathrm{x}=0-0.03$ is still within MPB. 
Table 1 The NBT-0.06B $\mathrm{B}_{1+\mathrm{x}} \mathrm{T}$, composition (sample) depending on the extra concentrations of $\mathrm{Ba}^{+2}$ from $\mathrm{A}, \mathrm{x}=0.00$ to $\mathrm{D}, \mathrm{x}=0.03$; samples density $\left(\mathrm{gm} \mathrm{cm}^{-3}\right)$, comparing with the theoretical density (\%) which is $\left(\rho=6 \mathrm{gm} \mathrm{cm}^{-3}\right)$, and the relative permittivity $\left(\varepsilon_{\mathrm{r}}\right)$, dielectric $\operatorname{loss}(\tan \delta)$ both at $1 \mathrm{kHz}$ and $\mathrm{RT}$ the depolarization temperature $\left(T_{d}\right)$ values $0.0 \leq \mathrm{x} \leq 0.03$ in present work and from the literatures

\begin{tabular}{|c|c|c|c|c|c|c|c|}
\hline \multirow[t]{2}{*}{$\begin{array}{l}\text { Composition (sample nume) } \\
0.94 \mathrm{NBT}-0.06 \mathrm{~B}_{1+\mathrm{x}} \mathrm{T}\end{array}$} & \multicolumn{2}{|c|}{$\begin{array}{l}\text { Lattice } \\
\text { parameters }(\AA)\end{array}$} & \multirow[t]{2}{*}{$\begin{array}{l}\text { Density ( }(\rho) \\
\mathrm{gm} \mathrm{cm}^{-3}\end{array}$} & \multirow{2}{*}{$\begin{array}{l}\text { Compare with } \\
\text { theoretical } \\
\text { density\% }\end{array}$} & \multirow{2}{*}{$\begin{array}{l}\text { Depolarization } \\
\text { temperature }\left(\boldsymbol{T}_{\boldsymbol{d}}\right) \\
\left({ }^{\circ} \mathrm{C}\right)\end{array}$} & \multirow{2}{*}{$\begin{array}{l}\text { Relative } \\
\text { permittivity }\left(\boldsymbol{\varepsilon}_{\mathbf{r}}\right) \\
\text { at } R T\end{array}$} & \multirow[t]{2}{*}{$\begin{array}{l}\text { Dielectric loss } \\
(\tan \delta) \text { at } R T\end{array}$} \\
\hline & $a=b$ & $\mathrm{c}$ & & & & & \\
\hline NBT-0.06BT $(\mathrm{A}, \mathrm{x}=0.0)$ & 5.488 & 13.505 & 5.697 & 94.95 & 125 & 1178 & 0.042 \\
\hline $\begin{array}{l}\text { NBT-0.06B }{ }_{1+0.01} \mathrm{~T}(\mathrm{~B} \\
\quad \mathrm{x}=0.01)\end{array}$ & 5.487 & 13.437 & 5.661 & 94.35 & 85 & 1468 & 0.046 \\
\hline $\begin{array}{l}\mathrm{NBT}-0.06 \mathrm{~B}_{1+0.02} \mathrm{~T}(\mathrm{C} \\
\quad \mathrm{x}=0.02)\end{array}$ & 5.494 & 13.505 & 5.718 & 95.55 & 85 & 1472 & 0.045 \\
\hline $\begin{array}{l}\text { NBT-0.06B }{ }_{1+0.03} \mathrm{~T}(\mathrm{D} \\
\mathrm{x}=0.03)\end{array}$ & 5.493 & 13.505 & 5.678 & 94.63 & 115 & 1266 & 0.040 \\
\hline
\end{tabular}

The measurement of the lattice parameters ( $a, b$ and $c$ ) reveals that the extra $\mathrm{Ba}$ content has slightly changed $\mathrm{a}, \mathrm{b}$ and $\mathrm{c}$ from $\mathrm{a}=\mathrm{b}=5.488 \AA, \quad \mathrm{c}=13.505 \AA$ to $\mathrm{a}=\mathrm{b}=5.493 \AA, \mathrm{c}=13.505 \AA$ for Samples $\mathrm{A}$ to $\mathrm{D}$ respectively (Table 1 ). Sample $\mathrm{C}$ presents the biggest lattice parameters $(\mathrm{a}=\mathrm{b}=5.494 \AA, \mathrm{c}=13.505 \AA$ ).

Comparing the ionic radii of the A-site cations of $\mathrm{Na}^{+}$ $(1.39 \AA), \mathrm{Bi}^{3+}(1.31 \AA)$ and $\mathrm{Ba}^{2+}(1.61 \AA)$ (coordination No. 12) according to Hume-Rothery rules, $\mathrm{Ba}^{2+}$ in NBT$0.06 \mathrm{~B}_{1+\mathrm{x}} \mathrm{Ti}$ could replace $\mathrm{Na}^{+}$but seems to be difficult to replace $\mathrm{Bi}^{3+}$ because the radius difference between $\mathrm{Bi}^{3+}$ and $\mathrm{Ba}^{2+}$ is more than $15 \%$ [19]. Yoon et al. [19] reported that the c/a ratio increased with adding more extra $\mathrm{Ba}$ content and reached the maximum at $x=0.02$. Thus the increase in $\mathrm{Ba}^{2+}$ content would lead to the improvement of the tetragonality of $\mathrm{BT}$ in $\mathrm{NBT}-0.06 \mathrm{~B}_{1+\mathrm{x}} \mathrm{T}$ by compensating for the loss in $\mathrm{Ba}$ during the sintering stage. However, any extra $\mathrm{Ba}^{2+}$ content more than $\mathrm{x}=0.02$ would not go to increase the c/a ratio because the c/a ratio was saturated at 0.02, and therefore consequently the extra $\mathrm{Ba}$ would precipitate into a secondary phase [19], but in this study the second phase was not identified up to $\mathrm{x}=0.03$, probably due to the amount of the secondary phase being too small to be tested by XRD.

Figure 2 shows the surface morphology of the NBT$0.06 \mathrm{~B}_{1+\mathrm{x}} \mathrm{T}$ ceramics by SEM. The average grain size was reduced from $1.7 \mu \mathrm{m}$ at $\mathrm{x}=0.00$ to $1.61,1.31,1.52$ at $\mathrm{x}=0.01,0.02$ and 0.03 , respectively. Increasing $\mathrm{Ba}^{2+}$ led to a sharp reduction in the grain size and reached the lowest value at $\mathrm{x}=0.02$. In general, $\mathrm{Ba}^{2+}$ behaves as an inhibitor of the grain growth in NBT system. In lead-based ceramics, such as PZT and PLZT (La-containing PZT), similar effect was also observed when lead was substituted with barium $[17,19,20]$. All the samples showed a density $94.63 \pm 0.333 \mathrm{~g} / \mathrm{cm}^{3}$ as shown in Table 1 . Density measurements revealed that Sample A, B and D at $\mathrm{x}=0.0$,
0.01 and 0.03 have a similar density value; however, Sample $C$, at $\mathrm{x}=0.02$ has a higher density.

\subsection{Effects of extra barium on dielectric properties}

Figure 3 shows the temperature dependence of the dielectric properties of poled NBT $-0.06 \mathrm{~B}_{1+\mathrm{x}} \mathrm{T}$ from RT up to $150{ }^{\circ} \mathrm{C}$ at different frequencies $(1,10$ and $100 \mathrm{kHz})$. The relative dielectric permittivity $\left(\varepsilon_{\mathrm{r}}\right)$ and the dielectric loss tangent $(\tan \delta)$ show a strong dependence upon Ba content and temperature. The $\varepsilon_{r}$ increased with temperature for all samples; however, the $\varepsilon_{\mathrm{r}}$ showed increasing at $\mathrm{x}=0.01$, and 0.02 at room temperature and this can be related to extra $\mathrm{Ba}^{2+}$. The extra $\mathrm{Ba}$ at $\mathrm{x}=0.01$ compensated the deficiency in $\mathrm{Ba}$ in $\mathrm{BT}$ side and rectified the tetragonality in NBT. The excess $\mathrm{Ba}$ up to 0.02 can then replace cations in the A-site of the $\mathrm{NBT}-0.06 \mathrm{~B}_{1+\mathrm{x}} \mathrm{T}$ perovskite structure, so $\mathrm{Ba}^{2+}$ will replace $\mathrm{Na}^{+}$according to the radius matching rules and the donor behaviour of $\mathrm{Ba}$ will make the domain wall motion easier resulting in the increase of the dielectric properties of NBT-0.06B $\mathrm{B}_{1+0.02} \mathrm{~T}$ [12].

The $\varepsilon_{\mathrm{r}}$ values at $\mathrm{x}=0.01$ and 0.02 were close to 1500 for both compositions whereas the $\varepsilon_{\mathrm{r}}$ values at $\mathrm{x}=0.0$ and 0.03 at RT were near 1225 . However, at $T_{d}$, and $150{ }^{\circ} \mathrm{C}$, the $\varepsilon_{r}$ for the samples at $\mathrm{x}=0.01$ and 0.02 increased to around 2000 and $2150\left(T_{d}\right)$, and above for both compositions $2500\left(150{ }^{\circ} \mathrm{C}\right)$ respectively. However, the $\varepsilon_{r}$ values for the samples at $\mathrm{x}=0.00$ and 0.03 were relatively low, which are around 2250 .

\subsection{Effects of extra barium on depolarization temperature}

Depolarization temperature $\left(T_{d}\right)$ is a parameter that has not clearly been defined [10], but the European standard on piezoelectric properties has defined it as the reduction of 
Fig. 1 XRD patterns of NBT$0.06 \mathrm{~B}_{1+\mathrm{x}} \mathrm{TiO}_{3}$ ceramics where, a $\mathrm{x}=0.00,0.01,0.02$ and 0.03 ; b expansion at $2 \theta$ from $39.6^{\circ}$ to $40.6^{\circ}$ and $\mathbf{c}$ expansion at $2 \theta$ from $45.0^{\circ}$ to $48.0^{\circ}$

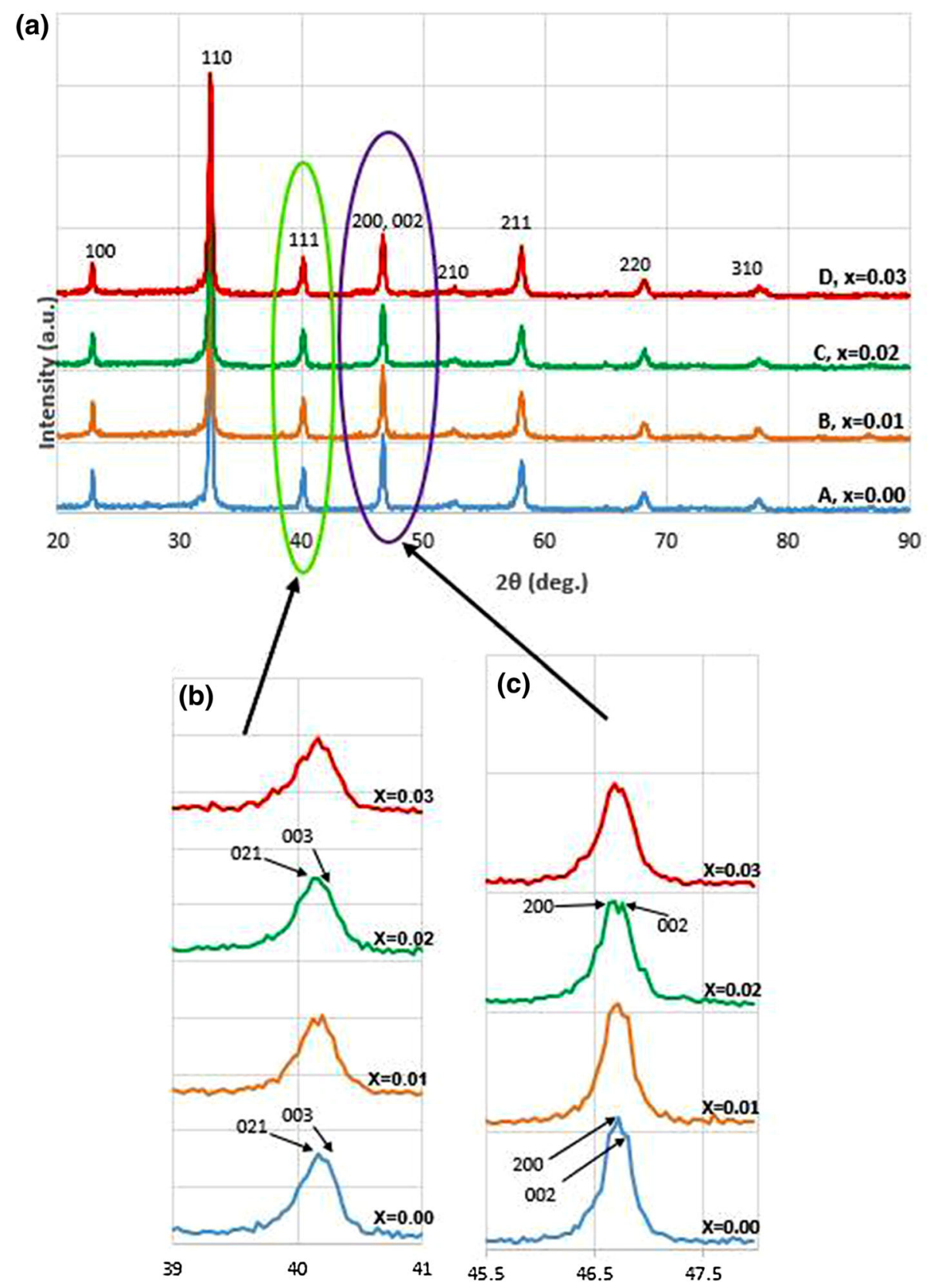

remnant polarization because of temperature and other influences [21]. However, there are other definitions of $T_{d}$ such as the steep reduction of remnant polarization [7], or the phase transition temperature from ferroelectric $(F E)$ to anti-ferroelectric $(A F E)$ or to relaxor anti-ferroelectric or to relaxor [8, 22-25].

In this study, $T_{d}$ was identified from the measurement of the dielectric loss $(\tan \delta)$ versus temperature. Figure 3 shows that the $T_{d}$ of the NBT-0.06 $\mathrm{B}_{1+0.00} \mathrm{~T}$ was at $\sim 125^{\circ} \mathrm{C}$ and decreased to $\sim 85^{\circ} \mathrm{C}$ at $\mathrm{x}=0.01$ and 0.02 , and then rises to $\sim 115{ }^{\circ} \mathrm{C}$ at $\mathrm{x}=0.03$. The reduction in $T_{d}$ is probably due to the formation of A-site vacancies with increasing $\mathrm{Ba}$ content in $\mathrm{NBT}-0.06 \mathrm{~B}_{1+\mathrm{x}} \mathrm{T}$ structures. In ferroelectric NBT-BT perovskite structure, the ferroelectric domain stability is affected by the coupling between ferroelectric $\left(\mathrm{BO}_{6}\right)$ and A-site cations, and the stability of the ferroelectric domains will be reduced when vacancies are generated between the octahedral $\left(\mathrm{BO}_{6}\right)$ ferroelectric and A-site cations. In this study, $\mathrm{Ba}^{2+}$ content at $\mathrm{x}=0.01-0.02$ created A-site vacancies so the stability of the ferroelectric domain reduced as a result inducing the phase change from ferroelectric $(F E)$ to relaxor anti-ferroelectric (relaxor AFE) and fast reduction by $40{ }^{\circ} \mathrm{C}$ in depolarization temperature $\left(T_{d}\right)[14,18,21]$. With a further increase of $\mathrm{Ba}^{2+}$ to $\mathrm{x}=0.03$, which is more than $\mathrm{Ba}^{2+}$ saturation content $(\mathrm{x}=0.02)$, the $T_{d}$ was decreased by only 

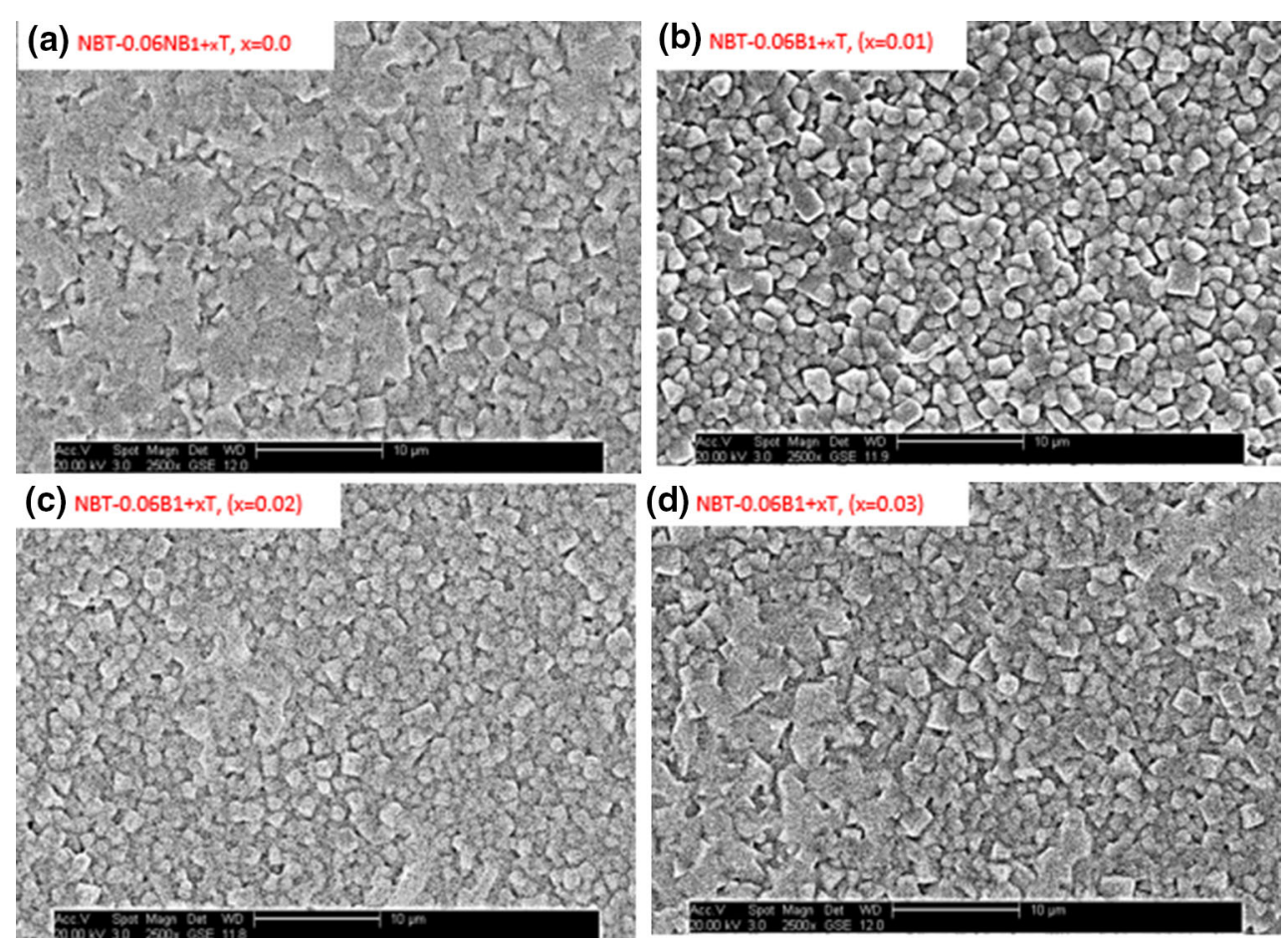

Fig. 2 The SEM surface morphology, NBT-0.06B ${ }_{1+\mathrm{x}} \mathrm{T}$ where, $\mathrm{x}=0.00(\mathbf{a}) ; \mathrm{x}=0.01(\mathbf{b}) ; \mathrm{x}=0.02(\mathbf{c}) ; \mathrm{x}=0.03(\mathbf{d})$

about $10{ }^{\circ} \mathrm{C}$, because there were less vacancies in A-site due to minimal $\left(\mathrm{Ba}^{2+} / \mathrm{Na}^{+}\right)$replacement and more ferroelectric domain wall stability $[9,14,26]$. The value of the $T_{d}$ of NBT-0.06BT in this work is close to that reported in the literature $\left(\sim 123{ }^{\circ} \mathrm{C}\right)$ but the depolarization temperature of the NBT- $-0.06 \mathrm{~B}_{1+\mathrm{x}} \mathrm{T},(0.01 \leq \mathrm{x} \leq 0.02)$ is lower than $123{ }^{\circ} \mathrm{C}$ [27]. Table 1 lists the values of relative dielectric permittivity $\left(\boldsymbol{\varepsilon}_{r}\right)$ and dielectric $\operatorname{loss}(\tan \delta)$ at RT and depolarization temperatures $\left(T_{d}\right)$ at $1 \mathrm{kHz}$ achieved in this work.

\subsection{Effects of extra barium on the pyroelectric properties}

The calculation of the figure of merits (FOMs) is based on the values of pyroelectric coefficient $(p)$, relative dielectric permittivity $\left(\varepsilon_{\mathrm{r}}\right)$, the dielectric loss tangent $(\tan \delta)$ and the specific heat $\left(C_{v}\right)$. There are several numbers of FOMs which are more appropriate to certain pyroelectric materials applications [6, 27] and are derived from these application requirements.

Pyroelectric coefficient $(p)$ and the FOMs were analysed by using the following equations: $[5,15,28]$

$$
\begin{aligned}
I p & =p A \frac{d T}{d t} \\
F_{i} & =\frac{p}{C_{v}}
\end{aligned}
$$

$$
\begin{aligned}
\boldsymbol{F}_{\boldsymbol{v}} & =\frac{\boldsymbol{p}}{C_{v} \varepsilon_{o} \varepsilon_{\mathrm{r}}} \\
\boldsymbol{F}_{\boldsymbol{D}} & =\frac{\boldsymbol{p}}{\boldsymbol{C}_{\boldsymbol{v}} \sqrt{\boldsymbol{\varepsilon}_{o} \boldsymbol{\varepsilon}_{r} \tan \boldsymbol{\delta}}} .
\end{aligned}
$$

where $T$ is absolute temperature, $\boldsymbol{t}$ the time, $\boldsymbol{I}_{p}$ the pyroelectric current, $\boldsymbol{F}_{\boldsymbol{i}}$ the high current $(\boldsymbol{i})$ detectivity figure of merit, $F_{v}$ the high voltage $(V)$ detectivity figure of merit, $\boldsymbol{F}_{\boldsymbol{D}}$ high detectivity figure of merit, and $C_{v}$ the specific heat (2.8 $\mathrm{JK}^{-1} \mathrm{~cm}^{-3}$, quoted fm [29]).

The pyroelectric current of $\mathrm{NBT}-0.06 \mathrm{~B}_{1+\mathrm{x}} \mathrm{T}$, $(0.00 \leq \mathrm{x} \leq 0.03)$ ceramics was measured from RT to $T_{d}$ or $90{ }^{\circ} \mathrm{C}$ that is our equipment upper limit.

Table 2 shows the pyroelectric coefficient $(p)$ and the figures of merit (FOMs) values of the NBT- $0.06 \mathrm{~B}_{1+\mathrm{x}} \mathrm{T}$, $(0.00 \leq \mathrm{x} \leq 0.03)$ at $R T, T_{d}$ or $90{ }^{\circ} \mathrm{C}$. The $p$ values varied with the $\mathrm{Ba}^{2+}$ content, and increased from $2.9 \times 10^{-4}$ $\left(\mathrm{C} \mathrm{m}^{-2}{ }^{\circ} \mathrm{C}^{-1}\right)$ to $3.54 \times 10^{-4}\left(\mathrm{C} \mathrm{m}^{-2}{ }^{\circ} \mathrm{C}^{-1}\right)$ when $\mathrm{x}$ increased from 0.00 to 0.02 at RT. All the samples showed a great increase in $p$ when the measurement temperature increased from $20{ }^{\circ} \mathrm{C}$ to $T_{d}$ or $90{ }^{\circ} \mathrm{C}$. This great increase in $p$ at $T_{d}$ or $90{ }^{\circ} \mathrm{C}$ was caused by the increase of $\boldsymbol{I}_{p}$ induced by the reorientation of ferroelectric domain and phase transition in MPB. When the temperature rises from RT to $T_{d}$, the phase transition from ferroelectric $(F R)$ to relaxor antiferroelectric (relaxor $A F R$ ) started, and thus a sharp change in polarization resulted in a significant increase in $p$ at $T_{d}[15]$. 
(a) Sample A

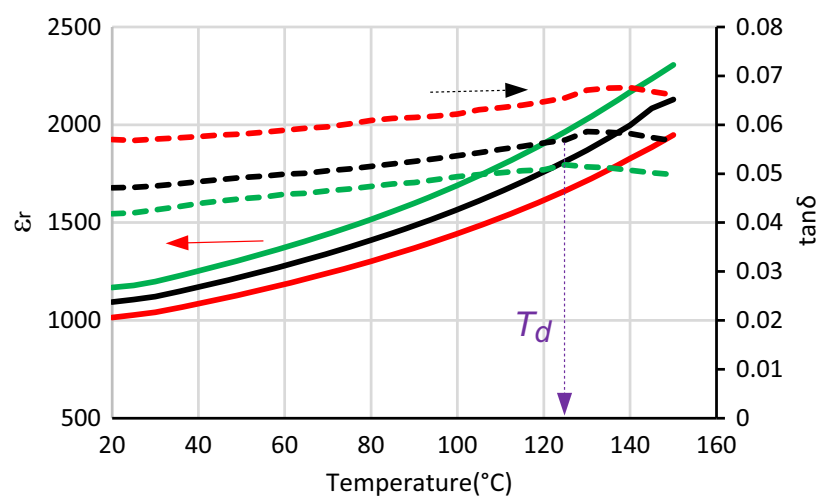

(c) Sample C

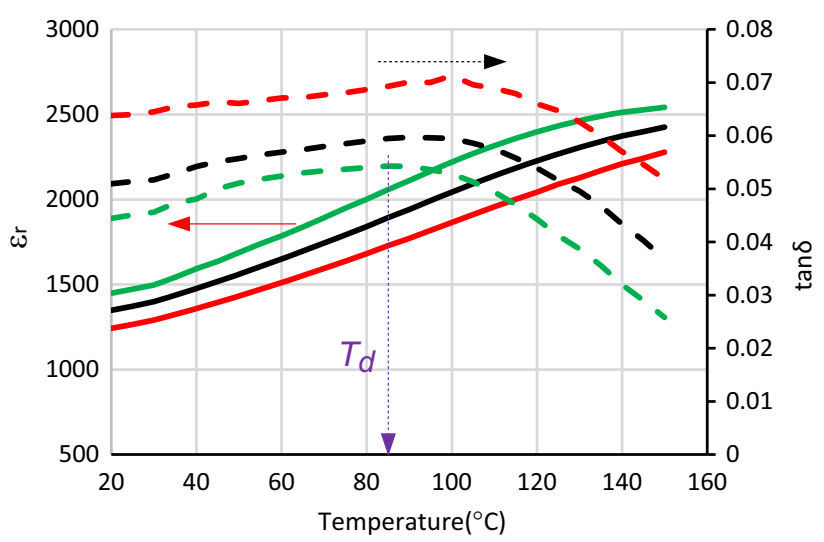

Fig. 3 The change of the relative permittivity $\left(\varepsilon_{\mathrm{r}}\right)$ and loss tangent $(\tan \delta)$ with changing temperature $\left({ }^{\circ} \mathrm{C}\right)$ form RT up to $150{ }^{\circ} \mathrm{C}$, for the NBT $-0.06 B_{1+\mathrm{x}} \mathrm{T}$, where $0.0 \leq \mathrm{x} \leq 0.03$ form $\mathbf{a}-\mathbf{d}$ in three different

The $T_{d}$ for Sample B $(\mathrm{x}=0.01)$ and $\mathrm{C}(\mathrm{x}=0.02)$ is below $90{ }^{\circ} \mathrm{C}$ and for Sample A $(\mathrm{x}=0.00)$ and $\mathrm{D}$ $(\mathrm{x}=0.03)$ above $90^{\circ} \mathrm{C}$, which explained why Sample B and $\mathrm{C}$ had a greater increase in $p$ than Sample A and D. According to Anton et al. [7], the $T_{d}$ determination depends on the highest value of the dielectric loss tangent, which may consistently generate higher $T_{d}$ than other methods such as the thermally stimulated depolarization current; therefore the $T_{d}$ for Sample A and D might actually be less than $\sim 125$ and $\sim 110{ }^{\circ} \mathrm{C}$, as a result that the observed increase in $p$ for Sample A and D could be related to the beginning of the phase transition in these samples.

The increase of $\mathrm{Ba}$ content up to $\mathrm{x}=0.02$ reduces the distortion in the perovskite structure due to the replacement of $\mathrm{Na}^{+}(1.39 \AA)$ by $\mathrm{Ba}^{2+}(1.61 \AA)$, which can shift the $T_{d}$ to lower temperature [28]. Further increase in Ba content to $\mathrm{x}=0.03$ would lead to the appearance of a secondary phase or the replacement of $\mathrm{Na}^{+}$. Thus, the depolarization temperature at $\mathrm{x}=0.03$ shows a slight increase than that at $\mathrm{x}=0.01-0.02[14,28,30]$. Table 2 also lists the $p$ value $\left(4.14 \times 10^{-4} \mathrm{C} \mathrm{m}^{-2}{ }^{\circ} \mathrm{C}^{-1}\right)$ of a typical PZT ceramic (b) Sample B

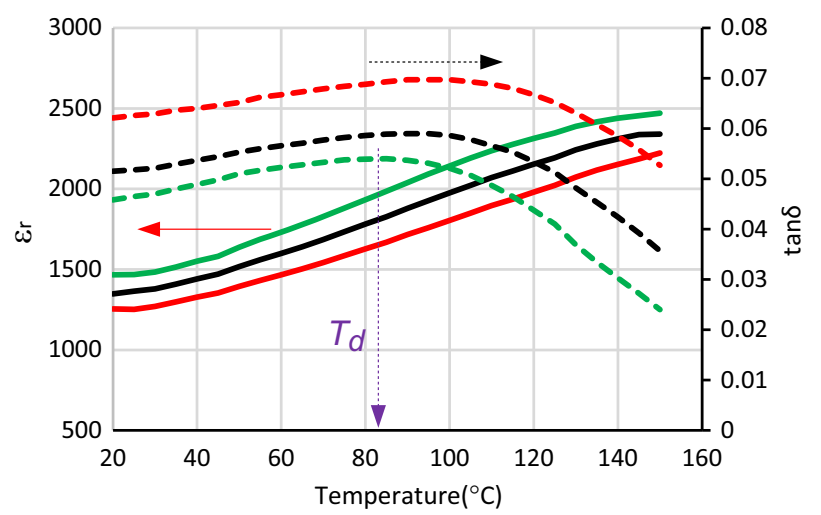

(d) Sample D

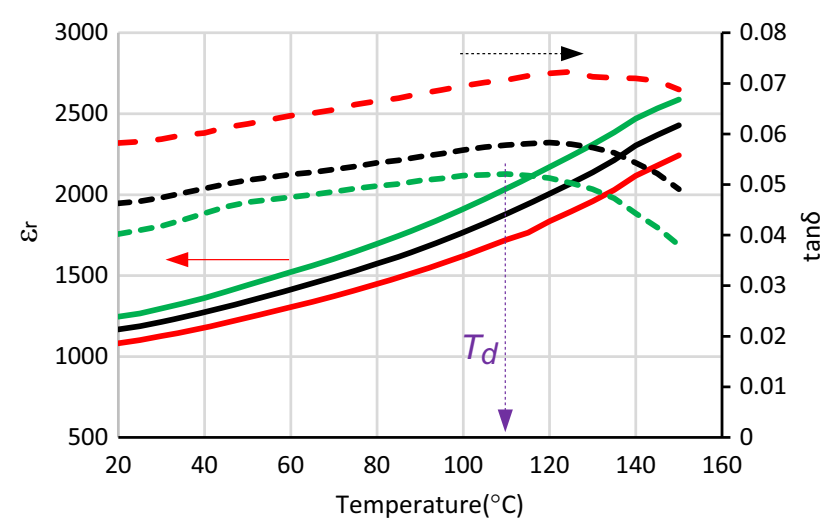

frequencies $(1,10$ and 100) $\mathrm{kHz}$. The identified of the depolarization temperature $\left(T_{d}\right)$ from the dielectric loss lines at $1 \mathrm{kHz}$

measured at RT as a reference. The prepared NBT$0.06 \mathrm{~B}_{1+\mathrm{x}} \mathrm{T}$ at $\mathrm{x}=0.01-0.03$ in this research show the comparable pyroelectric coefficients $\left(3.30-3.5 \times 10^{-4}\right.$ $\left.\mathrm{C} \mathrm{m}{ }^{-2}{ }^{\circ} \mathrm{C}^{-1}\right)[5,6,9]$.

The values of $\boldsymbol{F}_{\boldsymbol{i}}, \boldsymbol{F}_{\boldsymbol{v}}$ and $\boldsymbol{F}_{\boldsymbol{D}}$ of the NBT- $-0.06 \mathrm{~B}_{1+\mathrm{x}} \mathrm{T}$ samples $(0.00 \leq \mathrm{x} \leq 0.03)$ at $\mathrm{RT}, T_{d}$ or $90{ }^{\circ} \mathrm{C}$ are also shown in Table 2. The $\boldsymbol{F}_{\boldsymbol{i}}$ value increased from $1.04 \times 10^{-10}(\mathrm{~m} / \mathrm{V})(\mathrm{x}=0.00)$ to $1.24 \times 10^{-10}(\mathrm{~m} / \mathrm{V})$ $(\mathrm{x}=0.02)$ at $\mathrm{RT}$ and from $1.24 \times 10^{-10}(\mathrm{~m} / \mathrm{V})(\mathrm{x}=0.02)$ to $260 \times 10^{-10}(\mathrm{~m} / \mathrm{V})(\mathrm{x}=0.02)$ at $T_{d}\left(85^{\circ} \mathrm{C}\right)$. The $\boldsymbol{F}_{\boldsymbol{i}}$ of Sample $\mathrm{C}(\mathrm{x}=0.02)$ at RT is very close to that for PZT $\left[1.415 \times 10^{-10}(\mathrm{~m} / \mathrm{V})\right][3]$. However, at $T_{d}\left(85^{\circ} \mathrm{C}\right)$ this sample $(\mathrm{x}=0.02)$ shows a much higher $p$ value $\left[260 \times 10^{-10} \quad(\mathrm{~m} / \mathrm{V})\right.$ than the best value $\left(\sim 7.33 \times 10^{-10}(\mathrm{~m} / \mathrm{V})\right]$ at $T_{d}\left(50{ }^{\circ} \mathrm{C}\right)$ reported by Gue et al. [15].

The $\boldsymbol{F}_{\boldsymbol{v}}$ values at RT and $T_{d}$ or $90{ }^{\circ} \mathrm{C}$ increased from $0.99 \times 10^{-2}\left(\mathrm{~m}^{2} \mathrm{C}^{-1}\right)$ at $\mathrm{x}=0.00$ to $1.05 \times 10^{-2}\left(\mathrm{~m}^{2} \mathrm{C}^{-1}\right)$ at $\mathrm{x}=0.03$. All these $\boldsymbol{F}_{\boldsymbol{v}}$ values exceed the value for PZT $[5,15,29,30] . \boldsymbol{F}_{\boldsymbol{v}}$ values increased at $T_{d}$ from $0.95 \times 10^{-2}$ to $164 \times 10^{-2} \mathrm{~m}^{2} / \mathrm{C}$ for Sample C $(\mathrm{x}=0.02)$. 
Table 2 Comparing the pyroelectric coefficients and the figures of merit $\left(F_{i}, F_{v}\right.$, and $\left.F_{D}\right)$ of the $\mathrm{NBT}-0.06 \mathrm{~B}_{1+\mathrm{x}} \mathrm{T}(0.00 \leq \mathrm{x} \leq 0.03)$ ceramic at frequency $1 \mathrm{kHz}$, at two different temperatures $\mathrm{RT}, \mathrm{T}_{\mathrm{d}}$ or $90{ }^{\circ} \mathrm{C}$ (due to equipment upper limit) with the other lead-free compositions and PZT

\begin{tabular}{|c|c|c|c|c|c|}
\hline Composition & $\begin{array}{l}p\left(\times 10^{-4} \mathrm{C} \mathrm{m}^{-2}{ }^{\circ} \mathrm{C}^{-1}\right) \\
\text { at } R T \text { or } T d\end{array}$ & $F_{i}\left(\times 10^{-10} \mathrm{~m} \mathrm{~V}^{-1}\right)$ & $\begin{array}{l}F_{v}\left(\times 10^{-2} \mathrm{~m}^{2} \mathrm{C}^{-1}\right) \\
\text { at f. } 1 \mathrm{kHz}\end{array}$ & $\begin{array}{l}F_{D}\left(\times 10^{-6} \mathrm{~Pa}^{-1 / 2}\right) \\
\text { at f. } 1 \mathrm{kHz}\end{array}$ & References \\
\hline NBT-0.06BT & 2.90 at $R T$ & 1.04 at $R T$ & 0.99 at $R T$ & 8.6 at $R T$ & This study \\
\hline NBT-0.06BT & 55.3 at $90{ }^{\circ} \mathrm{C}$ & 19.7 at $90{ }^{\circ} \mathrm{C}$ & 14 at $90{ }^{\circ} \mathrm{C}$ & 75.6 at $90{ }^{\circ} \mathrm{C}$ & This study \\
\hline NBT-0.06Ba ${ }_{1.01} T$ & 3.47 at $R T$ & 1.238 at $R T$ & 0.95 at $R T$ & 7.7 at $R T$ & This study \\
\hline NBT-0.06Ba ${ }_{1.01} T$ & 601 at $85{ }^{\circ} \mathrm{C}$ & 215 at $85{ }^{\circ} \mathrm{C}$ & 115 at $90{ }^{\circ} \mathrm{C}$ & 674 at $90{ }^{\circ} \mathrm{C}$ & This study \\
\hline NBT-0.06Ba $a_{1.02} T$ & 3.54 at $R T$ & 1.244 at $R T$ & 0.95 at $R T$ & 8.3 at $R T$ & This study \\
\hline NBT-0.06Ba ${ }_{1.02} T$ & 741 at $85{ }^{\circ} \mathrm{C}$ & 260 at $85{ }^{\circ} \mathrm{C}$ & 164 at $85{ }^{\circ} \mathrm{C}$ & 915 at $85{ }^{\circ} \mathrm{C}$ & This study \\
\hline NBT-0.06Ba ${ }_{1.03} T$ & 3.30 at $R T$ & 1.177 at $R T$ & 1.05 at $R T$ & 9.1 at $\boldsymbol{R T}$ & This study \\
\hline NBT-0.06Ba $a_{1.03} T$ & 73.1 at $90{ }^{\circ} \mathrm{C}$ & 26.12 at $90{ }^{\circ} \mathrm{C}$ & 15 at $90{ }^{\circ} \mathrm{C}$ & 83.9 at $90{ }^{\circ} \mathrm{C}$ & This study \\
\hline PZT & 4.14 at $R T$ & 1.415 at RT & 0.8 at $R T$ & 9.01 & {$[5,18]$} \\
\hline NBT-0.07BZT & 5.7 at $R T$ & 2.03 at $R T$ & 2.18 at $R T$ & 10.5 & {$[5,18]$} \\
\hline NBT-0.07BZT & 20.0 at $50^{\circ} \mathrm{C}$ & 7.33 at $50{ }^{\circ} \mathrm{C}$ & 6.60 at $50{ }^{\circ} \mathrm{C}$ & 33.6 at $50^{\circ} \mathrm{C}$ & {$[5,18]$} \\
\hline NBT-0.07BZT & 221 at $87^{\circ} \mathrm{C}$ & - & - & - & {$[5,18]$} \\
\hline BNKBT & 3.25 at $R T$ & 1.95 at $R T$ & 2.6 at $R T$ & 13.43 & {$[5,18]$} \\
\hline KNLNTS & 1.9 at $R T$ & 0.931 at $R T$ & 0.7 at $R T$ & 11.5 & {$[5,18]$} \\
\hline
\end{tabular}

The samples made in this study are given in bold

The values of $\boldsymbol{F}_{\boldsymbol{D}}$ at $\mathrm{RT}, T_{d}$ or $90{ }^{\circ} \mathrm{C}$ are shown in Table 2. The $\boldsymbol{F}_{\boldsymbol{D}}$ values increased with extra $\mathrm{Ba}^{2+}$ content at RT from $8.6 \times 10^{-6} \mathrm{~Pa}^{-1 / 2} \quad(\mathrm{x}=0.00)$ to $9.2 \times 10^{-6} \mathrm{~Pa}^{-1 / 2} \quad(\mathrm{x}=0.03)$. Giant values for $\boldsymbol{F}_{\boldsymbol{D}}$ achieved at $T_{d}$ for Samples $\mathrm{B}$ and $\mathrm{C}$ were 674 and $915\left(\times 10^{-6} \mathrm{~Pa}^{-1 / 2}\right)$ respectively. $\boldsymbol{F}_{\boldsymbol{D}}$ for PZT [5, 15, 29, 30] at RT is $9.01 \times 10^{-6} \mathrm{~Pa}^{-1 / 2}$ and Sample D showed a higher $\boldsymbol{F}_{\boldsymbol{D}}$ value than PZT (Table 2).

\section{Conclusion}

The NBT $-0.06 \mathrm{~B}_{1+\mathrm{x}} \mathrm{T}$ ceramics with extra $\mathrm{Ba}$ content were prepared by using conventional solid state synthesis route. The microstructure, dielectric, depolarization temperature and pyroelectric properties of these ceramics were dependent upon the $\mathrm{Ba}^{2+}$ content. The depolarization temperature shifted to around $85^{\circ} \mathrm{C}$ with increasing the $\mathrm{Ba}^{2+}$ content up to $\mathrm{x}=0.02$. The pyroelectric coefficient and figures of merits $\left(\boldsymbol{F}_{\boldsymbol{i}}, \boldsymbol{F}_{\boldsymbol{v}}\right.$ and $\left.\boldsymbol{F}_{\boldsymbol{D}}\right)$ all increase at RT when $\mathrm{Ba}^{2+}$ content increases to $\mathrm{x}=0.02$. The giant pyroelectric coefficient, $741 \times 10^{-4}\left(\mathrm{C} \mathrm{m}^{-2}{ }^{\circ} \mathrm{C}^{-1}\right)$, was obtained at $T_{d}$ when $\mathrm{Ba}^{2+}$ content increases to $\mathrm{x}=0.02$. The results for NBT $-0.06 B_{1+x}$ T obtained in this study indicate that NBT$0.06 \mathrm{~B}_{1+\mathrm{x}} \mathrm{T}$ are promising candidates for pyroelectric applications in a wide temperature range.

Open Access This article is distributed under the terms of the Creative Commons Attribution 4.0 International License (http://crea tivecommons.org/licenses/by/4.0/), which permits unrestricted use, distribution, and reproduction in any medium, provided you give appropriate credit to the original author(s) and the source, provide a link to the Creative Commons license, and indicate if changes were made.

\section{References}

1. Sustainable development and Environment EC Directive on WEEE and ROHS in electrical and electronic equipment. www. dti.gov.uk

2. T. Takenaka, K. Maruyama, K. Sakata, $\left(\mathrm{Bi}_{1 / 2} \mathrm{Na}_{1 / 2}\right) \mathrm{TiO}_{3}-$ $\mathrm{BaTiO}_{3}$ system for lead-free piezoelectric ceramics. Jap. J. Appl. Phys. 30, 2236 (1991). doi:10.1143/JJAP.30.2236

3. X. Wang, $\mathrm{X}$. Tang, $\mathrm{H}$. Chan, Electromechanical and ferroelectric properties of $\left(\mathrm{Bi}_{1 / 2} \mathrm{Na}_{1 / 2}\right) \mathrm{TiO}_{3}-\left(\mathrm{Bi}_{1 / 2} \mathrm{~K}_{1 / 2}\right) \mathrm{TiO}_{3}-\mathrm{BaTiO}_{3}$ leadfree piezoelectric ceramics. Appl. Phys. Lett. 85, 91 (2004). doi: $10.1063 / 1.1767592$

4. X. Ma, L. Xue, L. Wan, S. Yin, Q. Zhou, Y. Yan, Synthesis, sintering, and characterization of BNT perovskite powders prepared by the solution combustion method. Ceram. Int. 39, 8147-8152 (2013). doi:10.1016/j.ceramint.2013.03.088

5. S.T. Lau, C.H. Cheng, S.H. Choy, D.M. Lin, K.W. Kwok, H.L.W. Chan, Lead-free ceramics for pyroelectric applications. J. Appl. Phys. 103, 10-13 (2008). doi:10.1063/1.2927252

6. S. Patel, A. Chauhan, S. Kundu, N.A. Madhar, B. Ilahi, R. Vaish, K.B.R. Varma, Tuning of dielectric, pyroelectric and ferroelectric properties of $0.715 \mathrm{Bi}_{0.5} \mathrm{Na}_{0.5} \mathrm{TiO}_{3}-0.065 \mathrm{BaTiO}_{3}-0.22 \mathrm{SrTiO}_{3}$ ceramic by internal clamping. AIP Adv. 5, 087145 (2015). doi:10.1063/1.4929328

7. E.M. Anton, W. Jo, D. Damjanovic, J. Rdel, Determination of depolarization temperature of $\left(\mathrm{Bi}_{1 / 2} \mathrm{Na}_{1 / 2}\right) \mathrm{TiO}_{3}$-based lead-free piezoceramics. J. Appl. Phys. 110, 1-14 (2011). doi:10.1063/1. 3660253

8. Y. Guo, M. Gu, H. Luo, Antiferroelectric phase and pyroelectric response in $\left(\mathrm{Na}_{\mathrm{y}} \mathrm{Bi}_{\mathrm{z}}\right) \mathrm{Ti}_{1-\mathrm{x}} \mathrm{O}_{3(1-\mathrm{x})}-\mathrm{xBaTiO}_{3}$ ceramics. J. Am. Ceram. Soc. 94, 1350-1353 (2011). doi:10.1111/j.1551-2916. 2011.04509.x 
9. X.J. Li, Z.Z. Xi, W. Long, P.Y. Fang, Synthesis of antiferroelectric $\left(\mathrm{Bi}_{0.534} \mathrm{Na}_{0.5}\right)_{0.94} \mathrm{Ba}_{0.06} \mathrm{TiO}_{3}$ ceramics with high phase transition temperature and broad temperature range by a solidstate reaction method. Chin. Sci. Bull. 58, 2893-2897 (2013). doi:10.1007/s11434-013-5972-2

10. J.-H. Cho, Y.-H. Jeong, J.-H. Nam, J.-S. Yun, Y.-J. Park, Phase transition and piezoelectric properties of lead-free $\left(\mathrm{Bi}_{1 / 2} \mathrm{Na}_{1 / 2}\right)$ $\mathrm{TiO}_{3}-\mathrm{BaTiO}_{3}$ ceramics. Ceram. Int. 40, 8419-8425 (2014). doi:10.1016/j.ceramint.2014.01.051

11. J. Suchanicz, U. Lewczuk, Effect of Ba addition on the structural, dielectric and ferroelectric properties of $\mathrm{Na}_{0.5} \mathrm{Bi}_{0.5} \mathrm{TiO}_{3}$ ceramics. Mater. Sci Poland 33, 414-417 (2015). doi:10.1515/msp-20150056

12. M. Chen, Q. Xu, B.H. Kim, B.K. Ahn, J.H. Ko, W.J. Kang, O.J. Nam, Structure and electrical properties of $\left(\mathrm{Na}_{0.5} \mathrm{Bi}_{0.5}\right)_{1-\mathrm{x}}$ $\mathrm{Ba}_{\mathrm{x}} \mathrm{TiO}_{3}$ piezoelectric ceramics. J. Eur. Ceram. Soc. 28, 843-849 (2008). doi:10.1016/j.jeurceramsoc.2007.08.007

13. C. Ma, X. Tan, Phase diagram of unpoled lead-free-ceramics. Solid State Commun. 150, 1497-1500 (2010). doi:10.1016/j.ssc. 2010.06.006

14. Q. Li, J. Wang, L. Ma, H. Fan, Z. Li, Large electrocaloric effect in $\left(\mathrm{Bi}_{0.5} \mathrm{Na}_{0.5}\right)_{0.94} \mathrm{Ba}_{0.06} \mathrm{TiO}_{3}$ lead-free ferroelectric ceramics by $\mathrm{La}_{2} \mathrm{O}_{3}$ addition. Mater. Res. Bull. 74, 57-61 (2016). doi:10.1016/ j.materresbull.2015.10.010

15. F. Guo, B. Yang, S. Zhang, F. Wu, D. Liu, P. Hu, Y. Sun, D. Wang, W. Cao, Enhanced pyroelectric property in $(1-\mathrm{x})\left(\mathrm{Bi}_{0.5} \mathrm{Na}_{0.5}\right) \mathrm{TiO}_{3}-\mathrm{xBa}\left(\mathrm{Zr}_{0.055} \mathrm{~T}_{\mathrm{i} 0.945}\right) \mathrm{O}_{3}$ : role of morphotropic phase boundary and ferroelectric-antiferroelectric phase transition. Appl. Phys. Lett. 103, 182906 (2013). doi:10. $1063 / 1.4828675$

16. R.L. Byer, C.B. Roundy, Pyroelectric coefficient direct measurement technique and application to a nsec response time detector. IEEE Trans. Sonics Ultrason. 19, 333-338 (1972). doi:10.1109/T-SU.1972.29679

17. C. Xu, D. Lin, K.W. Kwok, Structure, electrical properties and depolarization temperature of $\left(\mathrm{Bi}_{0.5} \mathrm{Na}_{0.5}\right) \mathrm{TiO}_{3}-\mathrm{BaTiO}_{3}$ lead-free piezoelectric ceramics. Solid State Sci. 10, 934-940 (2008). doi:10.1016/j.solidstatesciences.2007.11.003

18. M. Rawat, K.L. Yadav, A. Kumar, P.K. Patel, N. Adhlakha, J. Rani, Structural, dielectric and conductivity properties of $\mathrm{Ba}^{2+}$ doped $\left(\mathrm{Bi}_{0.5} \mathrm{Na}_{0.5}\right) \mathrm{TiO}_{3}$ ceramic, advanced. Mater. Lett. 3, 286-292 (2012). doi:10.5185/amlett.2012.2322

19. M.S. Yoon, N.H. Khansur, S.C. Ur, The effect of pre-milling/presynthesis process and excess $\mathrm{Ba}$ on the microstructure and dielectric/piezoelectric properties of nano-sized $0.94\left[\left(\mathrm{Bi}_{0.5} \mathrm{Na}_{0.5}\right) \mathrm{TiO}_{3}\right]-$ $0.06\left[\mathrm{Ba}_{(1+\mathrm{x})} \mathrm{TiO}_{3}\right]$. Ceram. Int. 36, 1265-1275 (2010). doi:10. 1016/j.ceramint.2010.01.011
20. Y. Hiruma, K. Yoshii, H. Nagata, T. Takenaka, Investigation of phase transition temperatures on $\left(\mathrm{Bi}_{1 / 2} \mathrm{Na}_{1 / 2}\right) \mathrm{TiO}_{3}-\left(\mathrm{Bi}_{1 / 2} \mathrm{~K}_{1 / 2}\right)$ $\mathrm{TiO}_{3}$ and $\left(\mathrm{Bi}_{1 / 2} \mathrm{Na}_{1 / 2}\right) \mathrm{TiO}_{3}-\mathrm{BaTiO}_{3}$ lead-free piezoelectric ceramics by electrical measurements. Ferroelectrics 346, 114-119 (2007). doi:10.1080/00150190601180471

21. R. Ranjan, A. Dviwedi, Structure and dielectric properties of $\left(\mathrm{Na}_{0.50} \mathrm{Bi}_{0.50}\right)_{1-\mathrm{x}} \mathrm{Ba}_{\mathrm{x}} \mathrm{TiO}_{3}: 0 \leq \mathrm{x} \leq 0.10$. Solid State Commun. 135, 394-399 (2005). doi:10.1016/j.ssc.2005.03.053

22. E. Sapper, S. Schaab, W. Jo, T. Granzow, J. Rödel, Influence of electric fields on the depolarization temperature of Mn-doped $(1-\mathrm{x}) \mathrm{Bi}_{1 / 2} \mathrm{Na}_{1 / 2} \mathrm{TiO}_{3}-\mathrm{xBaTiO}_{3}$. J. Appl. Phys. 111, 014105 (2012). doi:10.1063/1.3674275

23. S. Zhang, A.B. Kounga, E. Aulbach, W. Jo, T. Granzow, H. Ehrenberg, J. Rödel, Lead-free piezoceramics with giant strain in the system $\mathrm{Bi}_{0.5} \mathrm{Na}_{0.5} \mathrm{TiO}_{3}-\mathrm{BaTiO}_{3}-\mathrm{K}_{0.5} \mathrm{Na}_{0.5} \mathrm{NbO}_{3}$. II. Temperature dependent properties. J. Appl. Phys. 103, 034108 (2008). doi: $10.1063 / 1.2838476$

24. W. Jo, J.E. Daniels, J.L. Jones, X. Tan, P.A. Thomas, D. Damjanovic, J. Rödel, Evolving morphotropic phase boundary in leadfree $\left(\mathrm{Bi}_{1 / 2} \mathrm{Na}_{1 / 2}\right) \mathrm{TiO}_{3}-\mathrm{BaTiO}_{3}$ piezoceramics. J. Appl. Phys. 109, 014110 (2011). doi:10.1063/1.3530737

25. W. Jo, J. Daniels, D. Damjanovic, W. Kleemann, J. Rdel, Twostage processes of electrically induced-ferroelectric to relaxor transition in $0.94\left(\mathrm{Bi}_{1 / 2} \mathrm{Na}_{1 / 2}\right) \mathrm{TiO}_{3}-0.06 \mathrm{BaTiO}_{3}$. Appl. Phys. Lett. 102, 4 (2013). doi:10.1063/1.4805360

26. X. Li, P. Liu, Z. Xi, P. Fang, W. Long, X. Zhao, Effects of doping $\mathrm{Bi}$ and $\mathrm{Nd}$ on the phase transition and electric properties of $\left(\mathrm{Bi}_{1 / 2}\right.$ $\left.\mathrm{Na}_{1 / 2}\right) 0.94 \mathrm{Ba} 0.06 \mathrm{TiO}_{3}$ ceramics. J. Electroceram. 32, 86-91 (2014). doi:10.1007/s10832-013-9881-1

27. Q. Xu, D.P. Huang, M. Chen, W. Chen, H.X. Liu, B.H. Kim, Effect of bismuth excess on ferroelectric and piezoelectric properties of a $\left(\mathrm{Na}_{0.5} \mathrm{Bi}_{0.5}\right) \mathrm{TiO}_{3}-\mathrm{BaTiO}_{3}$ composition near the morphotropic phase boundary. J. Alloys Compd. 471, 310-316 (2009). doi:10.1016/j.jallcom.2008.03.078

28. S.R. Shannigrahi, F.E.H. Tay, K. Yao, R.N.P. Choudhary, Effect of rare earth (La, Nd, Sm, Eu, Gd, Dy, Er and $\mathrm{Yb}$ ) ion substitutions on the microstructural and electrical properties of sol-gel grown PZT ceramics. J. Eur. Ceram. Soc. 24, 163-170 (2004). doi:10.1016/S0955-2219(03)00316-9

29. Y.Z. Zhu, S.P. Lin, Y. Zheng, D.C. Ma, B. Wang, Improvement of pyroelectric figures of merit in zirconia-doped congruent lithium niobate single crystals. J. Mater. Sci. 51, 3155-3161 (2016). doi:10.1007/s10853-015-9625-5

30. J. Abe, M. Kobume, T. Nishimura, T. Yazaw, Y. Nakai, Effects of manganese addition on pyroelectric properties of $\left(\mathrm{Bi}_{0.5} \mathrm{Na}_{0.5}\right.$ $\left.\mathrm{TiO}_{3}\right)_{0.94}\left(\mathrm{BaTiO}_{3}\right) 0.06$ ceramics. Integr. Ferroelectr. 80, 87-95 (2006). doi:10.1080/10584580600656502 